\title{
Study on the Electrochemical Mechanism of the Comprehensive Recovery of Valuable Components from Spent Cemented Carbide
}

\author{
Hongguang Kang, Jidong Li , Jinlin Lu, Qian Wang, Yiyong Wang, Zhe Ning \\ School of Materials and Metallurgy, University of Science and Technology Liaoning, Anshan 114051, \\ China \\ *E-mail: lijidong2009@ustl.edu.cn
}

Received: 27 August 2020 / Accepted: 25 October 2020 / Published: 10 November 2021

\begin{abstract}
Spent cemented carbide contains a large number of valuable metals including tungsten and cobalt. To reasonably and effectively utilize the secondary resources of spent cemented carbide, Co and $\mathrm{WO}_{3}$ were recovered from spent cemented carbide by a combination of low-temperature electrochemical separation and high-temperature calcination. In a low-temperature $(298 \mathrm{~K})$ aqueous acid solution, a three-electrode system was used for electrochemical testing. The results show that on stainless steel cathodes, the deposition potential of Co(II) was between -0.6 and $-0.5 \mathrm{~V}$ (vs SCE). Electrodeposition was controlled by diffusion and was irreversible. The diffusion coefficient of $\operatorname{Co}(\mathrm{II})$ was $7.12 \times 10^{-7} \mathrm{~cm}^{2} \mathrm{~S}^{-1}$. The electrodeposition products were characterized by XRD and SEM, and the results showed that anode mud $\mathrm{H}_{2} \mathrm{WO}_{4}$ formed an orthorhombic crystal system. This $\mathrm{H}_{2} \mathrm{WO}_{4}$ was decomposed into $\mathrm{WO}_{3}$ by hightemperature calcination. The combination of low-temperature electrochemical separation and hightemperature calcination thus serves as an effective way to recover and separate valuable metals from spent alloys.
\end{abstract}

Keywords: Spent cemented carbides; Recovery; $\mathrm{WO}_{3}$; Cyclic voltammetry; Number of transferred electrons

\section{$\underline{\text { FULL TEXT }}$}

(C) 2021 The Authors. Published by ESG (www.electrochemsci.org). This article is an open access article distributed under the terms and conditions of the Creative Commons Attribution license (http://creativecommons.org/licenses/by/4.0/). 